\title{
A Secondary Cooling Pattern for Preventing Surface Cracks of Continuous Casting Slab*
}

\author{
By Tsutomu NOZAKI,** Jun-ichi MATSUNO, ** Kenji MURATA,** \\ Hiroshi OOI*** and Masanori KODAMA***
}

\begin{abstract}
Synopsis
In order to reduce the occurrence of surface defects of a continuous casting slab, the most suitable secondary cooling pattern was defined on the basis of the results of a theoretical calculation and a laboratory scale experiment on the thermal hysteresis similar to those of contimuous casting slabs. Moreover, it has been considered in this study that the transverse corner cracks could be related to the presence of precipitates appeared in the austenite grain boundaries.
\end{abstract}

(1) Transverse corner cracks are formed by the precipitates of AIN appeared on the grain boundary in the austenite region at the temperatures in the range of $700^{\circ}$ to $950^{\circ} \mathrm{C}$. Especially, the $\mathrm{AlN}$ formation is accelerated by reheating it at the temperature above $700^{\circ} \mathrm{C}$ from the lower temperature.

(2) From the experimental results on the roles of secondary cooling pattern and of temperature at the unbending roll in slabs continuously cast, it is ascertained that the occurrence of transverse corner crack is successfully prevented by the secondary cooling pattern, that is, a suitable cooling rate is less than $83^{\circ} \mathrm{C} / \mathrm{m}$ in the upper part of contimuous casting machine.

(3) The newly-devleoped spray cooling pattern is also effective for the reduction of longitudinal surface cracks.

\section{Introduction}

For certain types of grain-refined steels produced by the slab continuous casting machine of curved mold type, surface cracks mostly of the transverse type caused by the straightener give such a serious problem as the segregation and the accumulation of non-metallic inclusions. The transverse crack seriously impairs the product yield, when it occurs near the corner of slab (termed the transverse corner crack).

It is generally established that since elongation is reduced in the range of $700^{\circ}$ to $950^{\circ} \mathrm{C}$ for $40 \sim 50 \mathrm{~kg} /$ $\mathrm{mm}^{2}$ steels, a preventive practice for the occurrence of transverse corner cracks is to control the straightener temperature higher or lower than the above range. ${ }^{1,2}$ ) (These surface defects can be alleviated by allowing the straightener temperature to be higher or lower than the above range.) Anzai et al. ${ }^{3)}$ controlled the surface temperature of the straightener below $750^{\circ} \mathrm{C}$. Their conception was derived on the basis of the mechanical tests in which the reduction of area was lowered by $60 \%$ or less in the temperature range of $800^{\circ}$ to $900^{\circ} \mathrm{C}$.

Regarding the high temperature mechanical properties, some investigations ${ }^{4,5)}$ were made mainly on the temperature dependence and the effect of composition. Hasebe et al. ${ }^{6)}$ reported on the $\mathrm{Nb}$ and $\mathrm{Nb}-\mathrm{V}$ steels that the reduction of area which was $100 \%$ at $1000{ }^{\circ} \mathrm{C}$ or above was reduced to $60 \%$ or less in the range of $700^{\circ}$ to $900^{\circ} \mathrm{C}$. They also found that the plain carbon steel showed a slight reduction in constriction, though the reduction was not below $90 \%$ in the range of $800^{\circ}$ to $900^{\circ} \mathrm{C}$.

In regard to the high temperature mechanical properties of continuously cast steel, Ito et al. ${ }^{7)}$ found that the reduction of area becomes minimum at around $800^{\circ} \mathrm{C}$. They also found that the constriction quickly recovered at $800^{\circ} \mathrm{C}$ or above when the steel did not contain $\mathrm{Al}$, but such a recovery of constriction rate was limited to about $60 \%$ in the case of steel containing more than $0.03 \% \mathrm{Al}$.

Considering that the conventional researches have been focused mostly on the mechanical properties at a high temperature region and that any theoretical treatment has not been established on the secondary cooling pattern in the continuous casting process, the authors conceived a method whereby the surface temperature of continuously cast slabs can be calculated by means of the un-steady state heat conduction equation. The behavior of precipitations is clarified by the laboratory scale experiment simulating the cooling pattern of slab to the temperature curve obtained from the above calculation. As a result, the secondary cooling pattern has proved to be most desirable in preventing the occurrence of both transverse and longitudinal cracks.

\section{Experimental}

\section{Calculating Method of Surface Temperature}

The information concerning the hysteresis of slab surface temperature and the estimation of heat flux in each spray zone are essential in preventing the occurrence of surface cracks. In order to obtain the most suitable cooling pattern it is desirable to calculate the slab surface temperature from the operating conditions of the continuous casting machine. Though various theoretical models ${ }^{8-10}$ ) have been proposed on continuous casting, the authors adopted the one-dimensional solidification model ${ }^{11)}$ which ignored the heat flux from the narrow side of slab using the heat conduction analysis method conceived by some of the authors.

The one-dimensional unsteady state heat equation is shown in Eq. (1). The symbols used are summarized in Table 1 .

$$
\rho c u \frac{\partial \theta}{\partial z}=\frac{\partial}{\partial x}\left(\kappa \frac{\partial \theta}{\partial x}\right) \cdots
$$

* Orginally pubiished in Tetsu-to-Hagané, 62 (1976), 1503, in Japanese. English version received June 10 , 1977.

** Mizushima Research Laboratory, Research Laboratories, Kawasaki Steel Corp., Kawasaki-dori, Mizushima Kurashiki 712.

*** Mizushima Works, Kawasaki Steel Corp., Kawasaki-dori, Mizushima, Kurashiki 712. 
Table 1. List of symbols and their values

\begin{tabular}{|c|c|c|}
\hline Symbol & Definition & Unit \\
\hline$\theta$ & Temperature & ${ }^{\circ} \mathrm{C}$ \\
\hline$\theta_{s}$ & Surface temperature & ${ }^{\circ} \mathrm{C}$ \\
\hline$\theta_{w}$ & Temperature of cooling water & $20^{\circ} \mathrm{C}$ \\
\hline$\theta_{d}$ & Normalized temperature & $100^{\circ} \mathrm{C}$ \\
\hline$C$ & Specific heat & $\mathrm{cal} / \mathrm{g} \cdot{ }^{\circ} \mathrm{C}$ \\
\hline$U$ & Casting speed & $\mathrm{cm} / \mathrm{sec}$ \\
\hline$\rho$ & Density of steel & $7.4 \mathrm{~g} / \mathrm{cm}^{3}$ \\
\hline$x$ & Axis of direction of slab thickness & $\mathrm{cm}$ \\
\hline$z$ & $\begin{array}{l}\text { Axis of direction of slab with- } \\
\text { drawal }\end{array}$ & $\mathrm{cm}$ \\
\hline$\kappa$ & Thermal conductivity & $\mathrm{kcal} / \mathrm{m} \cdot \mathrm{hr} \cdot{ }^{\circ} \mathrm{C}$ \\
\hline$\kappa_{d}$ & Thermal conductivity at $\theta_{d}$ & $40 \mathrm{kcal} / \mathrm{m} \cdot \mathrm{hr} \cdot{ }^{\circ} \mathrm{C}$ \\
\hline$\kappa_{f}$ & $\begin{array}{l}\text { Thermal conductivity of mold } \\
\text { powder }\end{array}$ & $\mathrm{kcal} / \mathrm{m} \cdot \mathrm{hr} \cdot{ }^{\circ} \mathrm{C}$ \\
\hline$\kappa_{m}$ & Thermal conductivity of $\mathrm{Cu}$ mold & $330 \mathrm{kcal} / \mathrm{m} \cdot \mathrm{hr} \cdot{ }^{\circ} \mathrm{C}$ \\
\hline$\kappa_{w}$ & Thermal conductivity of water & $0.52 \mathrm{kcal} / \mathrm{m} \cdot \mathrm{hr} \cdot{ }^{\circ} \mathrm{C}$ \\
\hline$d_{m}$ & Thickness of $\mathrm{Cu}$ mold & $3.8 \mathrm{~cm}$ \\
\hline$d_{w}$ & Thickness of mold slit & $0.5 \mathrm{~cm}$ \\
\hline$d_{f}$ & Film thickness of mold flux & $0.005 \mathrm{~cm}$ \\
\hline
\end{tabular}

By introducing the reduced temperature $\phi$ and enthalpy $H$ into it, Eq. (1) is rewritten as Eq. (2).

$$
\frac{\partial H}{\partial z}=\frac{\kappa_{d}}{\rho u}\left(\frac{\partial^{2} \phi}{\partial x^{2}}\right)
$$

where, $\phi$ and $H$ are defined by Eqs. (3) and (4), respectively.

$$
\begin{gathered}
c=\partial H / \partial \theta \ldots \\
\dot{\phi}=\int_{\theta_{d}}^{\theta} \frac{\kappa}{\kappa_{d}} d \theta
\end{gathered}
$$

The following calculations are approximated by the mesh analysis which have already been proposed. ${ }^{11}$ ) In conclusion, Eq. (2) is shown as Eq. (5) in which $m$ and $n$ are integers of $x$ and $z$ directions, respectively.

$$
H_{m, n+1}=H_{m, n}+\frac{\kappa_{d}}{\rho u} \frac{\Delta z}{(\Delta x)^{2}}\left(\dot{\phi}_{m+1, n}-2 \dot{\phi}_{m},{ }_{n}+\dot{\phi}_{m-1}, n\right)
$$

Equations (6) and (7) are obtained by considering the boundary conditions, that is to say, slab surface $(x=0)$ and slab center $\left(x=x_{1}\right)$.

1) slab surface; $x=0 \quad(m=k)$

$$
-\kappa\left(\frac{\partial \theta}{\partial x}\right)=q_{x}=\frac{\kappa_{d}}{2\lrcorner x}\left(\phi_{k+1},{ }_{n}-\phi_{k-1},{ }_{n}\right) \ldots \ldots \ldots
$$

2) slab center; $x=x_{1}(m=l)$

$$
0=\phi_{l+1},{ }_{n}-\phi_{l-1}, n
$$

Substituting Eqs. (6) and (7) into Eq. (5), $\phi_{k-1, n}$ and $\phi_{l+1, n}$ are eliminated. Heat flux $q_{x}$ from the slab surface shown in Eq. (6) is a dominant factor for the solidification process. Then the mechanism of heat conduction is divided into two steps, i.e., in the mold and in the secondary cooling zone.

1) in the mold
Table 2. Chemical composition of sample prepared

\begin{tabular}{c|cccccc} 
Element & $\mathrm{C}$ & $\mathrm{Si}$ & $\mathrm{Mn}$ & $\mathrm{P}$ & $\mathrm{S}$ & $\mathrm{Al}$ \\
\hline $\mathrm{wt} \%$ & 0.18 & 0.37 & 1.33 & 0.020 & 0.017 & 0.039 \\
& & & \\
& $q_{x}=h_{x M}\left(\theta_{s}-\theta_{w}\right)$ & $\ldots \ldots \ldots \ldots \ldots \ldots(8)$
\end{tabular}

2) in the secondary cooling zone

$$
q_{x}=h_{x s}\left(\theta_{s}-\theta_{w}\right) \ldots
$$

where, $h_{x M}$ and $h_{x s}$ are the coefficients of heat conduction in the mold and in the secondary cooling zone, respectively. The latter is expressed by the following experimental formula ${ }^{12)}$ :

$$
h_{x S}=2.25 \times 10^{4} W^{0.55}\left(1-7.5 \times 10^{-3} \theta_{W}\right) / \alpha \ldots \ldots
$$

where, $W$ is the density of cooling water $\left(l / \mathrm{cm}^{2} \cdot \mathrm{min}\right)$ and $\alpha$ is the accommodation coefficient expressing the cooling efficiency in the case of uniform spray in the secondary cooling, and the value of $\alpha$ was four from the measurement of surface temperature at the straightener. Mesh widths are $5 \mathrm{~mm}$ in the $x$-direction, 0.5 to $100 \mathrm{~mm}$, and 10 to $100 \mathrm{~mm}$ or more in the $z$-direction, respectively.

\section{Experimental Method of AIN Precipitation}

As it is assumed that the AIN precipitation depends on the cooling rates, the precipitation quantities were compared with those obtained by the experiment simulating the heat cycles which affect continuously cast slabs.

The samples used in this experiment were made of continuously cast $50 \mathrm{~kg} / \mathrm{mm}^{2}$ slab, whose chemical analysis is shown in Table 2 . The sample shapes were classified into 3 types as shown in Fig. 1. With the C.A. thermocouple inserted into the center of the sample, the heat hysteresis was measured.

Sample (a) shown in Fig. 1 was $25 \mathrm{~mm}$ in thickness, which was subjected to the cooling process only in the furnace after heating up to $1200^{\circ} \mathrm{C}$ in a batch furnace. Thickess of sample (b) was $8 \mathrm{~mm}$ so as to facilitate a rapid repetition of reheating and cooling process. Sample (c) was heated with a high induction furnace and cooled by hard blowing of nitrogen gas, in order to reproduce the heat cycles simulating the actual condition.

Every experiment was performed after samples were homogeneously treated at $1200^{\circ} \mathrm{C}$ for more than 10 min. The time of one heat cycle was about $25 \mathrm{~min}$ so as to correspond with the actual process.

\section{Experimental Results}

\section{Surface Temperature of Conventional Spray Pattern}

The conventional spray pattern which caused the frequency of transverse corner crack is summarized in Table 3. The conditions listed in Table 3 are mathematically analyzed and the results obtained are shown in Table 3 and Fig. 2. The average cooling rate was $150^{\circ} \mathrm{C} / \mathrm{m}$ in the spray zone covering from the lower end of the mold to the spray zone 2 . The 
(a)
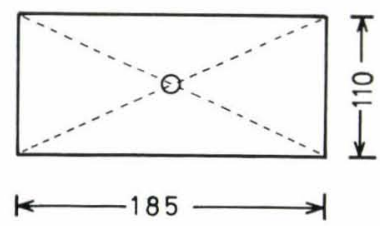

(b)

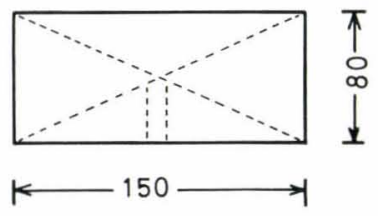

A.C. Thermo-couple

(c)

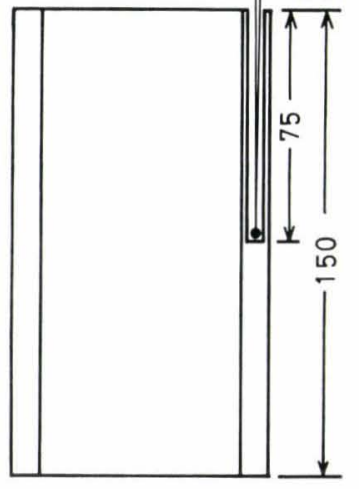

$\longleftarrow-80^{\phi} \longrightarrow$

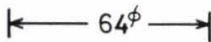

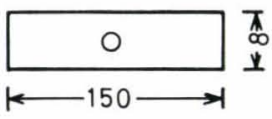
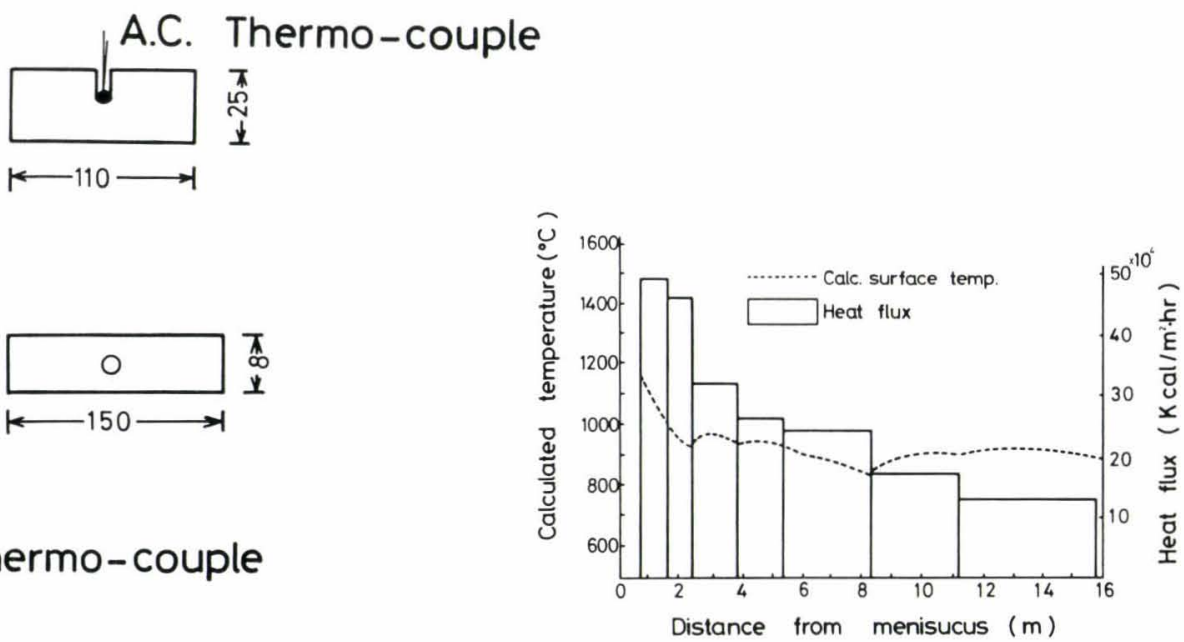

Fig. 2. Profile of the surface temperature for conventional spray pattern

Table 3. Distribution of cooling water, zone length and calculated surface temperature in conventional spray cooling pattern

\begin{tabular}{c|c|cccc} 
Zone & $\begin{array}{c}\text { Distance from } \\
\text { meniscus }\end{array}$ & $\begin{array}{c}\text { Cooling water } \\
(l / \mathrm{min})\end{array}$ & $\begin{array}{c}\text { Heat flux } \\
\left(\mathrm{kcal} / \mathrm{m}^{2} \cdot \mathrm{hr}\right)\end{array}$ & $\begin{array}{c}\text { Calculated surface } \\
\text { temperature } \\
\left({ }^{\circ} \mathrm{C}\right)\end{array}$ & $\begin{array}{c}\text { Cooling rate } \\
\left({ }^{\circ} \mathrm{C} / \mathrm{m}\right)\end{array}$ \\
\hline Mold & 0.63 & 2500 & & 1250 & 1030 \\
I & 1.47 & 207 & $4.91 \times 10$ & 920 & 190 \\
II & 2.31 & 227 & $4.60 \times 10$ & 930 & -45 \\
III & 3.81 & 207 & $3.12 \times 10$ & 930 & 0 \\
IV & 5.31 & 143 & $2.62 \times 10$ & 840 & -20 \\
V & 8.31 & 301 & $2.43 \times 10$ & 900 & -3 \\
II & 11.31 & 137 & $1.69 \times 10$ & 900 & -30
\end{tabular}

heat flux which was about $500000 \mathrm{kcal} / \mathrm{m}^{2} \cdot \mathrm{hr}$ at the portion near the mold decreased along with the withdrawal direction and the variation of the cooling rate was not uniform in the lower spray region.

Since the heat flux in the third zone and thereafter is lowered by $1 / 3$ or $1 / 4$ of the first and the second zones, the reheating and cooling are repeated in the third zone and thereafter until at the sixth zone where reheating takes place. Surface temperature is $900^{\circ} \mathrm{C}$ before the straightener.

In comparison with the cooling rates of these spray zones, the cooling rate in the upper part of the machine is $100^{\circ} \mathrm{C} / \mathrm{m}$ or more, but $-20^{\circ}$ to $+30^{\circ} \mathrm{C} / \mathrm{m}$ in the lower part. The characteristics of this conventional cooling pattern is a hard cooling in the upper part; namely, from meniscus to $5.31 \mathrm{~m}$, where a total consumption of cooling water is $58 \%$.

\section{Results of the Simulation Experiment of AIN Formation}

The experiment of the heat simulation cycle was made under the cosideration of available cooling patterns. The results obtained are shown in Figs. 3 and 4. In Type I of the heat cycle experiment it was adopted the cooling pattern showing the rapid cooling from the lower end of the mold. In Type II, the cooling pattern from the upper part of the machine to the straightener is softened as compared with that of Type I. These two types were regarded as the fundamental heat cycle patterns in the present experiment. Suffix a means a modification of Types I and II, and has a variation of temperature amplitude by $100^{\circ} \mathrm{C}$ in heating and cooling. Moreover, considering the alternating alignment of roll and spray, suffix b was used in the case of the heat cycle reproducing the cooling and heating. 


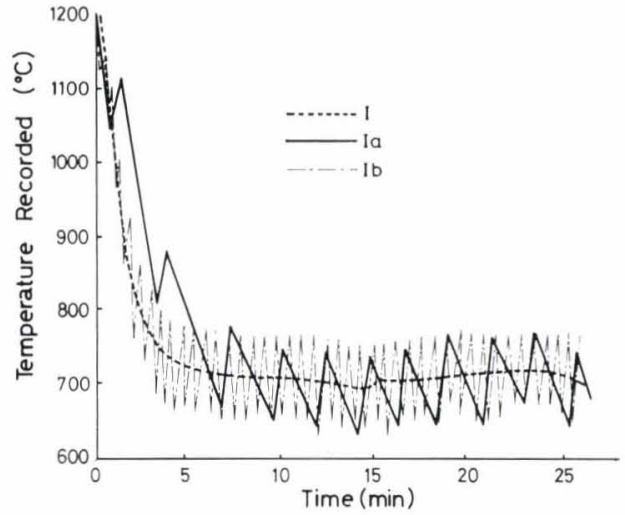

Fig. 3. Temperature curves of types I, Ia and Ib in the simulation experiment

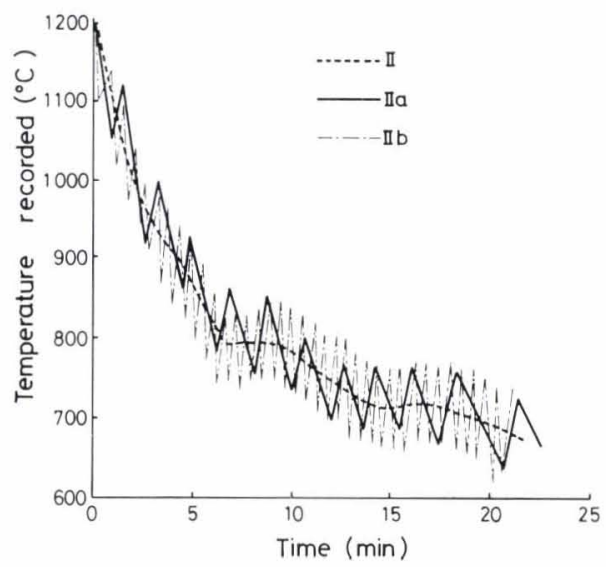

Fig. 4. Temperature curves of types II, IIa and IIb in the simulation experiment

The six experiments were made, and the results of chemical analysis of $\mathrm{N}_{\text {total }}$ and $\mathrm{N}_{\mathrm{AIN}}$ which were sampled in the vicinity of the positions where C.A. thermocouples are placed as shown in Table 4 . As shown in Figs. 3 and 4, the precipitation of AlN was not observed in the single cooling such as Types I and II.

On the other hand, in the pattern Ia, the precipitation of AlN is almost the same amount as that in the slab produced by an actual machine. In spite of the repeated hysteresis similar to that of Type Ia, the Type IIa pattern in which reheating was not made below $700^{\circ} \mathrm{C}$ gives the precipitates of only $9 \mathrm{ppm}$ of nitrogen as AlN. It was found, therefore, that the gradual cooling below $100^{\circ} \mathrm{C} / \mathrm{m}$ in the upper part of the machine is advantageous to prevent the precipitation of AlN. Moreover, the high frequency of surface cracks in the conventional cooling pattern was closely related to the AIN formation. The precipitation behavior is more clear in the cooling patterns Ib and IIb. Ratio of $\mathrm{N}_{\text {total }}$ to $\mathrm{N}_{\text {A1N }}$ was $70 \%$ in Type $\mathrm{Ib}$, and $31.5 \%$ in Type IIb. Also, in the Type Ib pattern, the precipitation in the case of air cooling was $14 \%$ higher than that of water cooling. This difference, however, was not observed at all in the Type IIb pattern.
Table 4. Amount of $\mathrm{N}_{\mathrm{AlN}}$ produced by heat treatment experiment

\begin{tabular}{c|c|c|c|c}
\hline Pattern & $\mathrm{N}_{\text {total }}$ & $\mathrm{N}_{\text {AlN }}$ & $\frac{\mathrm{N}_{\text {AIN }}}{\mathrm{N}_{\text {total }}} \times 100$ & $\begin{array}{c}\text { Treatment } \\
\text { after } \\
\text { experiment }\end{array}$ \\
\hline I & 55 & 8 & 14.5 & W.Q* \\
\hline Ia & 58 & 33 & 56.9 & W.Q \\
Ib & 50 & 35 & 70.0 & W.Q \\
Ib & 50 & 42 & 82.0 & A.C** \\
\hline II & 56 & 5 & 8.9 & W.Q \\
IIa & 56 & 9 & 16.1 & W.Q \\
IIb & 54 & 17 & 31.5 & W.Q \\
IIb & 52 & 16 & 30.8 & A.C \\
* water & quench & $* *$ air cool & & \\
\hline
\end{tabular}

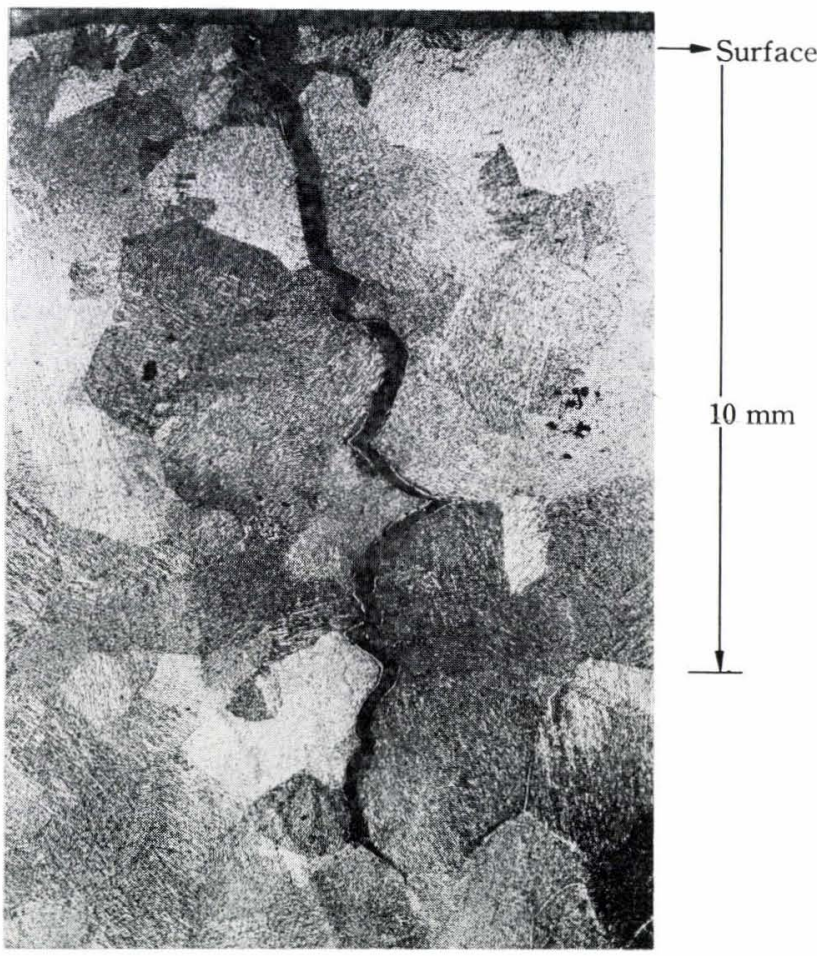

Photo. 1. Microscopic observation of transverse corner crack

\section{Cooling and Reheating in Secondary Cooling Zone}

The transverse corner cracks are easily formed in the steel containing aluminum of $0.020 \%$ or more. Furthermore, they tend to occur on the loose side of slab because of tension during the straightening and hardly on the fixed side. Cracks often appeared in the crystal grain boundary as shown in Photo. 1, and since they are not accompanied with the internal deoxidation and decarburization microstructures, it is assumed that the transverse corner crack is attributed to the brittle structure caused by the AlN formation in the boundaries.

As the water cooling practice on the loose side is the same as on the fixed side of slab surface, the AIN precipitation is equal on both sides, though the crack occurrence frequency is limitted on the loose side.

Iida et al. ${ }^{1)}$ observed the existence of AlN nearby cracks and the authors also have confirmed it by means 
of the electron-microscope of 2000 to 10000 magnifications. In order to grasp the tendency of crack formation in the cooling pattern, regression analysis was done for 216 heats of $50 \mathrm{~kg} / \mathrm{mm}^{2}$ steel for ship plate. The number of transverse corner cracks per $1 \mathrm{~m}$ slab length $Y$ is formulated in Eq. (11).

$$
\begin{aligned}
Y= & -1.98 X_{1}-4.30 X_{2}+265.98 X_{3}-552.71 X_{4} \\
& +307.09 X_{5}-171.85 X_{6}+36.72 \ldots \ldots \ldots \ldots \ldots
\end{aligned}
$$

where, $X_{1}$ : number of mold repetitions

$X_{2}$ : temperature difference between inlet and outlet of cooling plate jacket

$X_{3}$ : specific amount of water in the second zone

$X_{4}$ : specific amount of water in the fourth zone

$X_{5}$ : specific amount of water in the third and the fourth zones

$X_{6}$ : specific amount of water in the fifth zone.

From Eq. (11), it was found that the transverse corner cracks are easily formed by the strengthening of cooling in the upper part and by the alleviation of cooling in the lower part of the secondary cooling zone. The surface temperature transition of the conventional cooling pattern based on the heat conduction analysis described above became an issue for the cooling and heating of respective cooling zones of the machine. In the next study, the effect on the AIN precipitation of local heat cycle repetition of roll and spray was examined.

Two supplemental simulation experiments were performed on the Type Ia pattern of the highest AIN precipitation. The first case used a $15 \mathrm{~min}$ heat cycle instead of the $25 \mathrm{~min}$; and the second case decreased the amplitude from $\pm 50^{\circ}$ to $\pm 25^{\circ} \mathrm{C}$. These results are summarized in Table 5 and Fig. 5. The AIN precipitation by shortening the treating time was $40 \%$

Table 5. Effect of repetition of heat cycles on AIN formation

\begin{tabular}{c|cccc}
$\begin{array}{c}\text { Key of } \\
\text { Fig. }\end{array}$ & $\begin{array}{c}\text { Cooling } \\
\text { pattern }\end{array}$ & $\begin{array}{c}\mathrm{N}_{\text {total }} \\
(\mathrm{ppm})\end{array}$ & $\begin{array}{c}\mathrm{N}_{\mathrm{A} 1 \mathrm{~N}} \\
(\mathrm{ppm})\end{array}$ & $\begin{array}{c}\mathrm{N}_{\mathrm{A} 1 \mathrm{~N}} \\
\text { total } \\
(\%)\end{array}$ \\
\hline & $\mathrm{Ia}$ & 58 & 33 & 56.9 \\
\hline & shorten $>\mathrm{Ia}$ & 59.5 & 13.5 & 22.7 \\
$\ldots \ldots$ & $\mathrm{I} \pm 25^{\circ}$ & 58.0 & 19.0 & 33.6
\end{tabular}

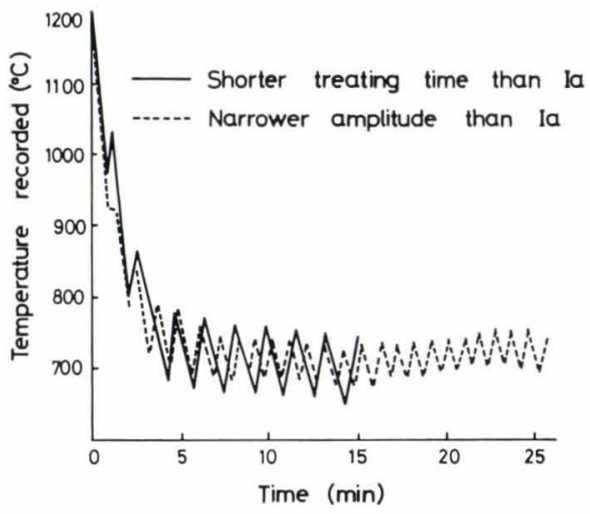

Fig. 5. Modifications of type Ia cooling pattern for Type Ia and $60 \%$ in the case of halved amplitude. These results suggest that the precipitation is mainly caused by the number of repetitions of the heat cycle of heating and cooling, and that the AIN precipitation can be controlled at the minimum level if there is no reheating process below $700^{\circ} \mathrm{C}$ even in the case of the same repetition number.

\section{Amplitude of Cooling and Heating in a Practical Machine}

We have calculated the temperature behavior caused by the repetition of roll and spray arrangement on the assumptions that:

(1) No heat conduction is made by roll.

(2) Spray water is effective only for slab.

(3) Equation (12) exists between the heat conduction coefficient $h_{\mathrm{sp}}^{\text {local }}$ and that of the zone.

$$
\Sigma l_{\mathrm{sp}} \cdot h_{\mathrm{sp}}^{\text {local }}=L \cdot h_{\mathrm{sp}}^{\text {average }}
$$

where, $\quad l_{\text {sp }}$ : the spray zone length between two rolls

$L$ : the total length of secondary cooling zone

$h_{\mathrm{sp}}^{\text {nverage }}$ as defined in Eq. (10)

The calculated result is shown in Fig. 6. The amplitude of surface temperature is $\pm 100^{\circ}$ to $\pm 200^{\circ} \mathrm{C}$ in the lower part of mold and in the position $3 \mathrm{~m}$ or more apart from meniscus, respectively. The serrated behavior of surface temperature is diminished at a depth of $33 \mathrm{~mm}$ from the slab surface.

\section{Effect of Secondary Cooling for the Upper Part on Surface Cracks}

Anzai et al. ${ }^{3)}$ reported that the occurrence of transverse corner cracks was reduced by keeping the surface temperature at the straightener outside the temperature range where crystal grain boundary becomes brittle. However, since it is assumed from the foregoing discussion that the occurrence of transverse corner cracks can significantly be prevented by controlling the spray pattern because of the relationship between the AIN precipitation and the slab cooling rate, it was confirmed by the following experiment as to which is dominant on the surface defects, whether temperature at the straightener or cooling pattern; namely,

$\mathrm{X}$ pattern: rapid cooling for the upper and lower parts

Y pattern: conventional cooling up to the part $8 \mathrm{~m}$

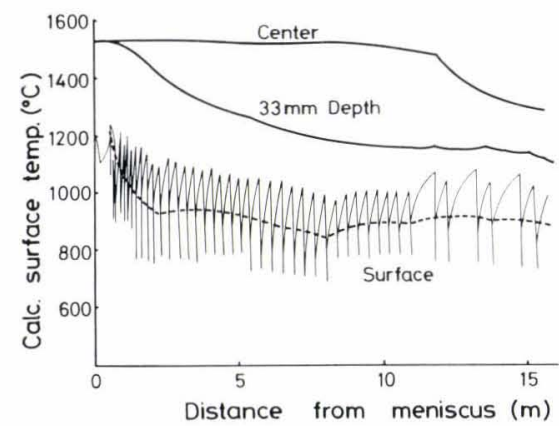

Fig. 6. Effect of roll pitches on the surface temperature of continuous casting slab 
apart from meniscus and strong cooling for the lower part

$\mathrm{Z}$ pattern: soft cooling at the top zone and conventional cooling at the lower zone, inversely to $\mathrm{Y}$ pattern.

The spray water quantities of these three cooling patterns and the calculated surface temperatures are shown in Table 6 and Fig. 7

\section{Experiment and Result of $\mathbf{X}, \mathbf{Y}$ and $\mathbf{Z}$ Methods}

Using the slabs of $220 \mathrm{~mm}$ thick for $50 \mathrm{~kg} / \mathrm{mm}^{2}$ steel, 12 heat experiments consisting of 4 heats each have been performed with an actual continuous casting machine. Table 7 shows the results of the number of transverse corner cracks, surface temperatures of the corner and wide face of slab measured with an optical pyrometer, and the AIN analytical values of the corresponding slab.

In $\mathrm{Z}$ pattern, no transverse corner cracks were detected. In contrast with $\mathrm{Z}$ pattern, $\mathrm{X}$ and $\mathrm{Y}$ spray patterns formed cracks of 38 and 50 in number, respectively. Corner temperatures were $700^{\circ} \mathrm{C}$ for $\mathrm{X}$ and $\mathrm{Y}$ patterns and $740^{\circ} \mathrm{C}$ for $\mathrm{Z}$ pattern. The AlN formations in the ratio of $\mathrm{N}_{\mathrm{AIN}}$ to $\mathrm{N}_{\text {total }}$ were $73 \%$ for $\mathrm{X}$

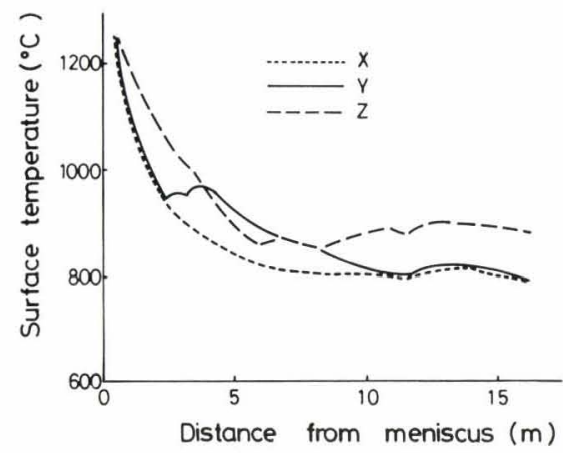

Fig. 7. Surface temperature of $\mathrm{X}, \mathrm{Y}$ and $\mathrm{Z}$ patterns

Table 6. Spray water and calculated surface temperature in $\mathrm{X}, \mathrm{Y}$ and $\mathrm{Z}$ patterns

\begin{tabular}{c|rr|rr|rr} 
Pattern & \multicolumn{2}{|c|}{$\mathrm{X}$} & \multicolumn{2}{c|}{$\mathrm{Y}$} & \multicolumn{2}{c}{$\mathrm{Z}$} \\
\hline Zone & $l /$ min & ${ }^{\circ} \mathrm{C}$ & $l / \mathrm{min}$ & ${ }^{\circ} \mathrm{C}$ & $l /$ min & ${ }^{\circ} \mathrm{C}$ \\
\hline Mold & 2000 & & 2000 & & 2000 \\
I & 356 & 1020 & 356 & 1020 & 180 & 1100 \\
II & 430 & 940 & 402 & 950 & 280 & 1020 \\
III & 500 & 870 & 409 & 960 & 370 & 960 \\
IV & 550 & 830 & 340 & 900 & 470 & 870 \\
V & 566 & 800 & 607 & 840 & 607 & 850 \\
VI & 566 & 800 & 566 & 800 & 319 & 880 \\
VII & 566 & 770 & 566 & 770 & 334 & 880
\end{tabular}

and $\mathrm{Y}$ patterns and $54.5 \%$ for $\mathrm{Z}$ pattern in the region of slab corner.

This tendency was clearly observed in the center region of the wide face of slab, namely, AIN was easily formed in the corner part as compared with the center portion. Especially, the $\mathrm{N}_{\mathrm{AlN}} / \mathrm{N}_{\text {total }}$ ratio of $\mathrm{Z}$ pattern was $9.6 \%$ in the wide face as compared with $54.5 \%$ for the corner part

From the above results, it was found that $\mathrm{X}$ and $\mathrm{Y}$ patterns which paid attention on the temperature of the unbending roll caused to form surface corner cracks, and further that, on the other hand, $\mathrm{Z}$ pattern which considered the secondary cooling pattern rather than the temperature of straightener formed no transverse corner crack. It was quite possible that the strong cooling caused the repeated heating and cooling, and especially reheating below $700^{\circ} \mathrm{C}$ as shown in Fig. 6.

From the fact that the cooling pattern for the top region of the continuous casting machine affects the formation of surface cracks, it is important to develop the most suitable spray pattern for the prevention of the occurrence of surface defects.

\section{A Secondary Cooling Pattern to Prevent the Occurrence of Surface Cracks}

The heterogeneous thickness of the solidified shell is caused in general by the undesirable choice of cooling for the mold and the secondary zone of the upper part, and such selection facilitates the AlN precipitation. A strong tendency of AIN formation which makes a brittle structure of crystal grain boundaries causes the occurrence of surface cracks owing to the thermal stress.

The conventional cooling type as shown in Fig. 2 which causes a noticeable reheating in each zone is not desirable for homogeneous growth of solidified shell. Moreover, there is a strong possibility that the reheating occurred below $700^{\circ} \mathrm{C}$, in the case of rapid cooling in the upper region of the machine. Therefore, we tried to develop such a spray cooling pattern as to give a minimum variation of surface temperature in each cooling zone, taking account of the previously mentioned heat cycle simulation experiment and the analysis of heat conduction equation.

Namely, the following conditions were introduced into the conventional cooling pattern.

1) Restriction of the cooling rate to the value less than $100^{\circ} \mathrm{C} / \mathrm{m}$, and decreasing the heat flux to the value less than $70000 \mathrm{kcal} / \mathrm{m}^{2} \cdot \mathrm{hr}$ in the upper region.

2) Conditioning of the cooling rate at about 10 to $20^{\circ} \mathrm{C} / \mathrm{m}$, and increasing the heat flux to 30000 to

Table 7. Experimental results of secondary spray patterns of $\mathrm{X}, \mathrm{Y}$ and $\mathrm{Z}$

\begin{tabular}{|c|c|c|c|c|c|c|c|}
\hline \multirow{2}{*}{$\begin{array}{l}\text { Cooling } \\
\text { pattern }\end{array}$} & \multirow{2}{*}{$\begin{array}{l}\text { No. of corner } \\
\text { cracks per } \\
\text { slab }\end{array}$} & \multicolumn{2}{|c|}{ Corner } & \multicolumn{2}{|c|}{ Center } & \multicolumn{2}{|c|}{ Surface temp. } \\
\hline & & $\begin{array}{c}\mathrm{N}_{\mathrm{AIN}} \\
(\mathrm{ppm})\end{array}$ & $\begin{array}{c}\mathrm{N}_{\mathrm{A} \backslash \mathrm{N}} / \mathrm{N}_{\text {total }} \\
(\%)\end{array}$ & $\begin{array}{c}\mathrm{N}_{\mathrm{AlN}} \\
(\mathrm{ppm})\end{array}$ & $\underset{(\%)}{\mathrm{N}_{\mathrm{A} 1 \mathrm{~N}} / \mathrm{N}_{\text {total }}}$ & $\begin{array}{c}\text { Corner } \\
\left({ }^{\circ} \mathrm{C}\right)\end{array}$ & $\begin{array}{c}\text { Center } \\
\left({ }^{\circ} \mathrm{C}\right)\end{array}$ \\
\hline $\mathrm{X}$ & 38 & 45 & 72.7 & 36 & 62.1 & 700 & 870 \\
\hline $\mathrm{Y}$ & 50 & 43 & 73.6 & 32 & 58.2 & 700 & 875 \\
\hline Z & 0 & 29 & 54.5 & 5 & 9.6 & 740 & 950 \\
\hline
\end{tabular}


$50000 \mathrm{kcal} / \mathrm{m}^{2} \cdot \mathrm{hr}$ in the lower region.

Next, we used Eq. (9) in which the heat flux is related to the surface temperature in order to obtain the heat conduction coefficient $h_{x s}$. Using Eq. (10), the spray water quantities per unit area can be calculated.

The surface temperature and heat flux calculated on the basis of the water quantities obtained are shown in Fig. 8 and Table 8 . The new spray cooling pattern is named "plateau" after its shape of Fig. 8.

The comparison of "plateau" pattern with the conventional one is as follows:

(1) The conventional pattern showed the rapid cooling in the upper region between 0.63 and $4 \mathrm{~m}$ from meniscus.

(2) In the region between 4 to $15.8 \mathrm{~m}$, the cooling rate was increased by an average of $18^{\circ} \mathrm{C} / \mathrm{m}$ in the case of "plateau" pattern.

(3) The surface temperature at the straightener was $900^{\circ} \mathrm{C}$ for the conventional and $700^{\circ} \mathrm{C}$ for the "plateau" pattern: The latter temperature was desirable for the prevention of the formation of brittle structure in crystal grain boundaries.

(4) The "plateau" pattern had little reheating at each zone.

The crator depth from meniscus of each spray pattern was $12.0 \mathrm{~m}$ for the conventional and $12.5 \mathrm{~m}$ for the "plateau" spray pattern, assuming the solidus temperature to be $1466^{\circ} \mathrm{C}$ for $50 \mathrm{~kg} / \mathrm{mm}^{2}$ steel.

Table 8. Calculated results of "plateau" secondary cooling pattern

\begin{tabular}{c|ccccc}
\hline Zone & $\begin{array}{c}\text { Heat flux } \\
\left(\mathrm{kcal} / \mathrm{m}^{2} \cdot \mathrm{hr}\right)\end{array}$ & $\begin{array}{c}\text { Surface } \\
\text { temp. } \\
\left({ }^{\circ} \mathrm{C}\right)\end{array}$ & $\begin{array}{c}\text { Calculated } \\
\text { cooling } \\
\text { water } \\
(l / \mathrm{min})\end{array}$ & $\begin{array}{c}\text { Calculated } \\
\text { surface } \\
\text { temp. } \\
\left({ }^{\circ} \mathrm{C}\right)\end{array}$ & $\begin{array}{c}\text { Cooling } \\
\text { rate } \\
\left({ }^{\circ} \mathrm{C} / \mathrm{m}\right)\end{array}$ \\
\hline I & $4.3 \times 10^{5}$ & 1140 & 90 & 1110 & 125 \\
II & $3.7 \times 10^{5}$ & 1060 & 118 & 1045 & 65 \\
III & $3.2 \times 10^{5}$ & 970 & 190 & 970 & 50 \\
IV & $3.0 \times 10^{5}$ & 910 & 190 & 905 & 43 \\
V & $2.6 \times 10^{5}$ & 850 & 321 & 840 & 22 \\
VI & $2.3 \times 10^{5}$ & 800 & 289 & 800 & 17 \\
VII & $1.9 \times 10^{5}$ & 775 & 319 & 770 & 6
\end{tabular}

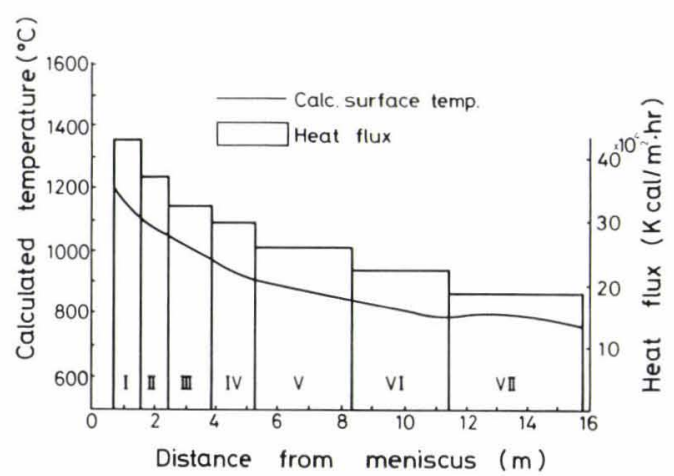

Fig. 8. Calculated surface temperature of "plateau "spray pattern

\section{Decrease of Surface Defects by Adopting the "Plateau" Cooling Pattern}

Table 9 shows the comparison of the "plateau" cooling pattern and the conventional pattern in terms of the surface defect rate and the average number of transverse corner cracks. The occurrence of transverse corner crack ceased completely by the "plateau" cooling pattern. Figure 9 shows the change in the frequency of transverse corner cracks from August, 1973 to June, 1974. After the employment of the "plateau" cooling pattern in February, 1974, the occurrence of transverse corner cracks on the slab surface has been reduced remarkably.

Longitudinal surface crack is caused by an improper choice of mold powder and a heterogeneous cooling in mold, since either of them leads to an uneven thickness of solidified shell, thus inviting a stress concentration. Lowering of the strength of solidified shell is attributable to the chemical component of steel such as $\mathrm{S}$ and $\mathrm{Al}$, the latter markedly increases the longitudinal surface cracks when they are contained $0.01 \%$ or more in the steel.

By adopting the "plateau" cooling pattern to 40 and $50 \mathrm{~kg} / \mathrm{mm}^{2}$ steels, the trend for the occurrence of longitudinal cracks was checked, and the index for the occurrence of longitudinal surface crack is summarized in Fig. 10, which indicates a drastic reduction of the index for the occurrence of longitudinal surface crack in both types of steels. It was made clear that the "plateau" cooling pattern has a sufficient effect in reducing the occurrence of longitudinal crack as well as transverse crack because it minimizes the variation of the solidified shell thickness and, in addition, suppresses the AIN precipitation.

Table 9. Comparison of transverse corner cracks between conventional and "plateau" spray patterns

\begin{tabular}{l|cccc}
$\begin{array}{c}\text { Cooling } \\
\text { pattern }\end{array}$ & Slab size & $\begin{array}{c}\text { No. of } \\
\text { heat }\end{array}$ & $\begin{array}{c}\text { Transverse } \\
\text { corner cracks } \\
\text { per two slabs temperature }\end{array}$ & $\begin{array}{c}\text { Observed } \\
\text { corner }\end{array}$ \\
\hline Conventional & $220 \times 1575$ & 17 & 87.8 & $800^{\circ} \mathrm{C}$ \\
"plateau" & $220 \times 1575$ & 16 & 0 & $730^{\circ} \mathrm{C}$
\end{tabular}

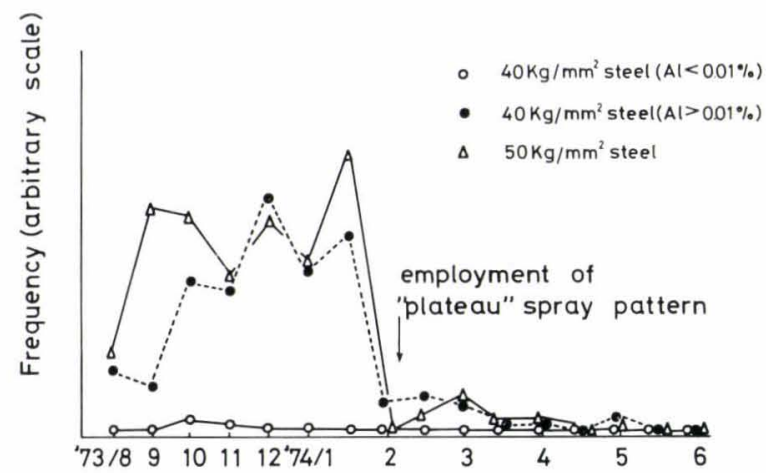

Fig. 9. Trends of the frequency of transverse corner cracks on the continuous casting slab after employment of "plateau" spray cooling pattern 


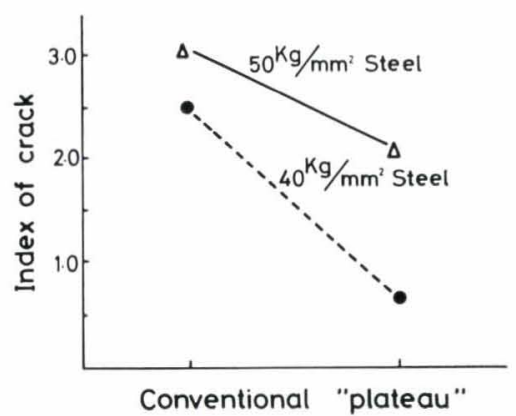

Fig. 10. Decrease of longitudinal surface cracks by the use of "plateau" spray pattern

\section{Discussion}

\section{Review of Existing Literatures}

In general, the continuous casting machine of curved mold type has a tendency to form transverse corner cracks, because the design of the machine makes the straightening of the cast slab inevitable. The preventive methods for the occurrence of these cracks have been devised on the basis of the mechanical properties of steel, especially such as elongation and reduction of area in high temperature range.

In regard to the spray cooling, Grosskurth et al. ${ }^{13}$ found that the transverse corner cracks were formed much easier in $50 \mathrm{~kg} / \mathrm{mm}^{2}$ steel than in $40 \mathrm{~kg} / \mathrm{mm}^{2}$ steel, when it cast by the machine with a radius of $9.8 \mathrm{~m}$. They explained that the tendency of crack formation was based on the high temperature brittleness. Then they chose the mild cooling of $0.6 \mathrm{l} / \mathrm{kg}$ in specific water quantities to avoid the brittle temperature.

According to their experiment, high temperature brittleness is started at $1200^{\circ} \mathrm{C}$, and the reduction of area is restored at the temperature below $800^{\circ} \mathrm{C}$. They found that the restoration temperature was changed by the steel grades. From the fact that the surface temperature of the mold end is about $1100^{\circ} \mathrm{C}$, the cast slab in the secondary cooling zone before the straightener suffers the high temperature brittleness. Therefore, their concept of straightening at high temperature by decreasing the amount of spray water is considered to be insufficient.

On the other hand, Schmidt and Josefsson ${ }^{2}$ reported that after they increased the water quantity from 1.0 to $1.6 \mathrm{l} / \mathrm{kg}$ steel, the percentage of rejects due to surface crack declined from $9.5 \%$ to $2.5 \%$.

They also reported that the transformation of $\gamma-\alpha-\gamma$ was effective for the prevention of the occurrence of transverse corner cracks, because the fine crystalline grain was formed. For the purpose of obtaining the fine grain, they proposed that the surface temperature at unbending point was reheated by $300^{\circ} \mathrm{C}$ to exceed the $\mathrm{Ac}_{3}$ temperature.

Ito et al. ${ }^{7)}$ reported that the reduction of area for the steel containing no aluminum became $50 \%$ at $800^{\circ} \mathrm{C}$ owing to the brittle transformation, in contrast with the result by Hasebe et al. ${ }^{6)}$ This brittleness was only found at $800^{\circ} \mathrm{C}$ and this temperature range was quite narrow.

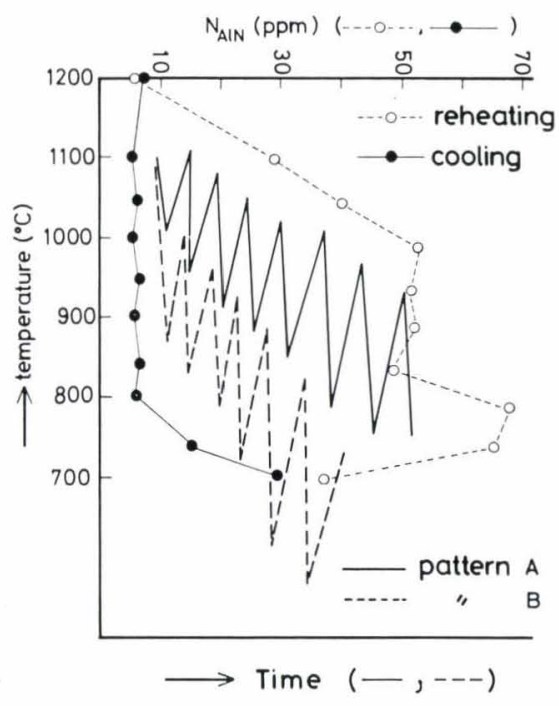

Fig. 11. Schematic representation of surface temperatures in the top region of spray zone with relation to the precipitation of AIN owing to Iida et al. ${ }^{11}$

The conventional researches on the transverse cracks described above paid attention only to the cooling method at unbending point and/or to the mechanical properties in (or within) the high temperature range. Therefore, the secondary cooling method related to the precipitation of AIN has not been taken up until the present work.

The steel containing $\mathrm{Nb}$ and/or $\mathrm{V}$ must carefully be studied from the viewpoint of cooling pattern, because of the conceivable precipitations such as NbC, $\mathrm{NbN}$ and $\mathrm{V}_{4} \mathrm{C}_{3}$ as well as AlN in question. ${ }^{14)}$

\section{AlN Formation}

Iida et al. ${ }^{11}$ experimentally showed the difference of precipitation between cooling and heating processes. As shown in Fig. 11, the AlN formation hardly occurred in the cooling process from $1200^{\circ}$ to $800^{\circ} \mathrm{C}$, and the ratio of $\mathrm{N}_{\text {AIN }}$ to $\mathrm{N}_{\text {total }}$ was in the level of $10 \%$. However, the AIN formation rose to $40 \%$ in the heating process from room temperature to $700^{\circ} \mathrm{C}$ and $90 \%$ at $800^{\circ} \sim 900^{\circ} \mathrm{C}$.

The present heat simulation experiments supported the result of Iida et al. ${ }^{1)}$ namely, the precipitation of AlN was about $10 \%$ for cooling alone and $70 \%$ for reheating and cooling repetition process.

Thermodynamics of the AIN formation have been proposed by Darken ${ }^{151}$ as Eq. (13).

$$
\log [\% \mathrm{Al}] \cdot[\% \mathrm{~N}]=-7400 / \mathcal{T}+1.95 .
$$

The equilibrium value of AIN calculated from the above equation is $150 \mathrm{ppm}$ at $800^{\circ} \mathrm{C}$ for the present aluminum and nitrogen contents of steel in question. Therefore, the actual precipitation in cast slab was found to be at most half of the equilibrium value.

When two cooling patterns $\mathrm{A}$ and $\mathrm{B}$ shown in Fig. 11 are considered, pattern $\mathrm{A}$ which is a gradual cooling in the upper part of machine does not reveal the reheating below $700^{\circ} \mathrm{C}$. In contrast with pattern $\mathrm{A}$, pattern $\mathrm{B}$ easily creates the AlN because of the heat repetition near $700^{\circ} \mathrm{C}$. Multiplication and disap- 
pearance of non-metallic inclusions are explained by the Ostwald ripening theory, which is also adopted to the present experiment on the AIN precipitation.

That is to say, in the case of type B cooling pattern, the nucleus of AlN is dissolved by the reheating process, except large nucleus over the critical size which acts as the AIN former in the next cooling stage. When the AIN precipitation is easily formed in the thin solidified shell at the bottom part of continuous casting mold, the austenite grain boundary becomes brittle as the origin of surface defects.

Accordingly, the fact that the frequency of longitudinal crack formation and transverse corner crack increases progressively with an increase of aluminum content is ascribed to the ease of AIN precipitation, as assumed by the solubility product in Eq. (13).

In the continuous casting, the prevention of the occurrence of transverse cracks has been practiced through the avoidance of brittle crack temperature by allowing the surface temperature either below $700^{\circ} \mathrm{C}$ or above $900^{\circ} \mathrm{C}$. However, our concept on the secondary cooling pattern based upon the theoretical and experimental examination can support the Type A pattern in regard to the prevention of AIN formation, if the brittle crack temperature region of grain boundary exists.

\section{Conclusion}

For the purpose of preventing the occurrence of surface defects of continuously cast slabs, the secondary cooling pattern was studied with the emphasis on its relations to the AlN precipitation in stead of the mechanical properties in a relatively high temperature range which hitherto constituted the main objective of many researches made on the secondary cooling practices. The authors aimed to develop the most suitable secondary cooling pattern through the laboratory experiments that simulated the actual machine and heating patterns used for continuous casting of slabs.

(1) The analytical result of heat conduction equation using the conventional spray cooling pattern which formed surface cracks showed the cooling rate to be $150^{\circ} \mathrm{C} / \mathrm{m}$ at the upper part of the machine, but at the lower part of the machine the cooling rate was not constant because of the repetition of heating and cooling.

(2) Analysis of $\mathrm{N}_{\text {total }}$ and $\mathrm{N}_{\mathrm{AIN}}$ in a heating cycle experiment using 6 types of cooling patterns simulat- ing the spray cooling of the actual casting operation showed that the precipitation of AlN tends to form by the repetition of cooling and heating, especially by the reheating cycle below $700^{\circ} \mathrm{C}$.

(3) By applying 3 types of spray patterns to the actual machine in order to ascertain a dominant factor affecting the transverse corner cracks, it was found that two spray patterns in which a major importance was placed on the surface temperature at unbending roll formed transverse corner cracks with $\mathrm{N}_{\mathrm{AIN}}$ to $\mathrm{N}_{\text {total }}$ ratio of 0.73 . On the other hand, the gradual cooling spray pattern used at the upper part of the machine formed no transverse corner cracks with the above ratio of only 0.54 .

(4) From the above findings, a "plateau " cooling pattern was developed as the most suitable one using the heat conduction equation assuming the ideal heat flux and surface temperature for each zone.

(5) The "plateau" cooling pattern has been contributed greatly not only to preventing the occurrence of transverse corner cracks but also to markedly decreasing the longitudinal surface cracks.

\section{REFERENCES}

1) Y. Iida, K. Moriwaki, N. Ueda and Y. Habu: Tetsu-toHagané, 59 (1973), S89.

2) L. Schmidt and A. Josefsson: Scand. J. Met., 3 (1974), 193.

3) T. Anzai, A. Yamagami, Y. Miyashita, E. Sakamoto, K. Suga and E. Sunami: Tetsu-to-Hagané, 60 (1974), 973 \& S37.

4) C. J. Adams and W. M. Williams: Can. Met. Quart., 9 (1970), 475 .

5) G. Komma, G. Vogt and K. Wunnenberg: Iron Steel Eng., (1973), June, 68.

6) S. Hasebe, T. Koga, T. Yamura and Y. Sujikawa: Tetsuto-Hagané, 58 (1972), S221.

7) A. Ito, Y. Settai and K. Sakumoto: Tetsu-to-Hagané, 61 (1975), S132.

8) E. A. Mizikar: Trans. Met. Soc. AIME, 239 (1967), 1749.

9) A. Moriyama and I. Muchi: Tetsu-to-Hagané, 54 (1968), 1127.

10) T. Kawawa, N. Nagaoka and S. Nemoto: Tetsu-to-Hagané, 56 (1970), S268.

11) J. Matsuno, H. Nakato and H. Ooi: Tetsu-to-Hagané, 60 (1974), 1023.

12) M. Shimada and M. Mitsuzuka: Tetsu-to-Hagané, 52 (1966), 1643.

13) N. Grosskurth, M. Hater and B. Redenz: Preprint of Metallurgical Seminor on Slab Casting in Zürich on Nov., 1973, CONCAST A. G., (1973).

14) T. Emi and H. Nakato: Private communication

15) L. S. Darken: J. Metals, 3 (1951), 1175. 